\title{
Density: Bulk in-situ or SG?
}

\author{
K.G. Lomberg
}

Affiliation:

1Pivot Mining Consultants, South Africa.

\section{Correspondence to:}

K.G. Lomberg

Email:

ken@pivotmining.co.za

Dates:

Received: 12 Nov. 2020

Revised: 18 Jul. 2021

Accepted: 8 Oct. 2021

Published: September 2021

\section{How to cite:}

Lomberg, K.G. 2021

Density: Bulk in-situ or SG?

Journal of the Southern African

Institute of Mining and Metallurgy,

vol. 121 , no. 9 , pp. 469-474

DOI ID:

http://dx.doi.org/10.17159/24119717/1423/2021

This paper was first presented at the SAMCODES 2020

Conference, 17 November 2020 Misty Hills Conference Centre, Muldersdrift, Johannesburg,

South Africa.

\section{Synopsis}

The density used to covert volume to tons is critical in determining the real in-situ tonnage of Mineral Resources. However, the methods used to determine density and the use of different technical terms are seen to be inconsistent throughout the industry. Probably the best discussion addressing the determination of density was presented by Lipton (2001). This paper does not try to replicate this excellent work, but rather to review current industry practice and present a comparison of the approach to density in public reporting. Some of the technical terms used in reporting and the common methods applied are also discussed.

\section{Keywords}

resource estimation, reporting, density measurement.

\section{Introduction}

While bulk density is a significant and critical component of a Mineral Resource estimation as it is a determinant of tonnage and metal content, it does not always get the same level of scrutiny as other data applied to the Mineral Resource estimation process. In the same way that a reliable estimate of grade is dependent on validated quality data and the use of a suitable and appropriate estimation methodology, so too is the appropriate estimation of the in-situ bulk density required. The underlying perceptions are that the in-situ bulk density is either not a critical factor, can easily be measured, or is constant in the deposit. None of these perceptions are true.

The Competent Person needs to understand the deposit, the need for density measurements, and the most appropriate method to apply to ensure that sufficient measurements are made to accurately estimate the density of the Mineral Resource. The aim of this paper is to highlight the important aspects of density and bulk density determination to provide the Competent Person with a reference as to the importance of density and how to apply it to Mineral Resource estimations. The paper does not provide the extensive details pertaining to the methods of density determination, as these have been previously published e.g. Lipton (2001), Lipton and Horton (2013).

\section{Importance of in-situ bulk density}

Dominy, Noppe, and Annels (2002) note that a Mineral Resource estimate should integrate a number of different facets, including:

> Geological data collection (drilling, mapping, etc.)

- Geotechnical data collection

- Sampling and assaying

> Bulk density determination

- Geological interpretation and modelling

- Grade/tonnage estimation

> Validation

> Resource confidence classification and reporting.

Each of these activities is associated with a level of inherent risk. Some of the risk can be mitigated if the right data is available and the appropriate estimation methodology is followed. It is noted that bulk density is one of the eight items highlighted and should be regarded and treated with the same level of diligence applied to the 'sampling and assaying' process. 


\section{Density: Bulk in-situ or SG?}

A review of many mine reports, Competent Persons Reports, and Technical Reports compiled in accordance with NI 43-101 shows that the attention to detail in respect of bulk density is often absent. To demonstrate this very poor approach to density, a study of 50 Technical Reports filed on the System for Electronic Document Analysis and Retrieval (https://www.sedar.com/; SEDAR) was undertaken by Arseneau (2013). The results are represented in Table I and Figure 1. It was concluded that although sample density data is collected, it is seldom analysed or discussed in much detail when generating a robust and supportable estimate of the bulk density. Only $20 \%$ of the reports reviewed utilized a density-specific data-set with the data being used to estimate the density independently for each block of the block model, while $18 \%$ of the reports reviewed did not discuss density at all. Some $58 \%$ of these documents reported a simple average density value, not taking the distribution of the data into consideration. These statistics emphasise the lack of importance attributed to density in the reports reviewed.

The importance of bulk density is also noted as it is included in the CIM Mineral Exploration Best Practice Guidelines (CIM, 2018) and The AusIMM Guide to Good Practice Monograph 23 (AusIMM, 2001). The CIM Mineral Exploration Best Practice Guidelines not only includes a specific section on bulk density measurement, but also emphasise the need to have representative samples at appropriate intervals for the determination of the bulk density. Similarly, the AusIMM Monograph 23 includes a chapter on bulk density - the paper by Lipton (2001) that has become the reference paper for bulk density measurement as it relates to Mineral Resource estimation. This paper highlights the frequent lack of attention to the accurate determination of bulk density, the factors that affect the measurements, and provides guidelines on how to measure bulk density.

\section{Bulk density vs specific gravity}

The in-situ bulk density is the density of the material as it occurs naturally, including all the pore spaces, voids, alteration, oxidation, intrusions etc. Clearly, the density determined on relatively small samples will likely not incorporate these features which contribute to void and variability (Dominy, Noppe, and Annels, 2002). Typically, the density measured also needs to include the drying of the sample and/or the determination of the moisture content of the sample, since for Resource Estimation purposes a dry density is required. The dry in-situ bulk density is the density of the material when the water has been removed from the pores and voids of the material. The logic is that the density (and tonnage) for the Resource Estimate should be at the same moisture basis as the grade (typically dry), so that when the metal content is calculated there is not fictious metal calculated from differences in moisture content. In contrast to the density required for metalliferous deposits, the in-situ bulk density for coal deposits is reported inclusive of the water (Preston and Sanders, 1993), while tonnage and quality (assay) data for coal is generally calculated and reported to a variety of moisture contents (in situ, air dry, as received, as delivered, and even 'bone dry').

Specific gravity or relative density is the relative density or ratio of the density of the material compared to water at $4^{\circ} \mathrm{C}$ and is reported as a dimensionless number. The specific gravity does not take account of the pore spaces, voids, alteration, oxidation, intrusions etc. Measurements are typically made in the laboratory on samples collected, dried, and crushed, thus ignoring the insitu bulk density requirement. Specific gravity is the appropriate measurement for metals and minerals when it may actually be equal to relative density, or may be thought of as the particle density (see also the pycnometer test). This is in distinct contrast to the case of natural rock samples which include various sources of voids.

\section{What must be measured}

The method of bulk density determination is often overlooked, but should be regarded as important as the assay technique

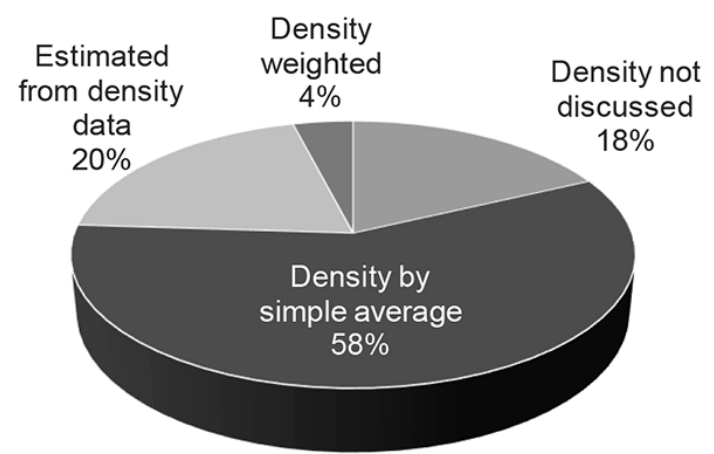

Figure 1-A summary of how density was reported in 50 SEDAR reports (Arseneau, (2013)

A summary of the approach to density in 50 SEDAR reports (Arseneau (2013)

\begin{tabular}{|c|c|c|c|c|c|c|}
\hline $\begin{array}{l}\text { Report } \\
\text { type }\end{array}$ & $\begin{array}{l}\text { Deposit } \\
\text { type }\end{array}$ & $\begin{array}{l}\text { Density not } \\
\text { discussed }\end{array}$ & $\begin{array}{c}\text { Density by } \\
\text { simple average }\end{array}$ & $\begin{array}{l}\text { Estimated from } \\
\text { density data }\end{array}$ & $\begin{array}{l}\text { Density } \\
\text { weighted }\end{array}$ & $\begin{array}{c}\text { Density as percentage } \\
\text { of assay data }\end{array}$ \\
\hline MRE & Precious metal & 4 & 14 & 4 & 0 & $14 \%$ \\
\hline PEA & Precious metal & 0 & 2 & 0 & 0 & $3 \%$ \\
\hline PFS & Precious metal & 3 & 1 & 1 & 0 & $3 \%$ \\
\hline MRE & Base metal & 0 & 3 & 3 & 0 & $11 \%$ \\
\hline PEA & Base metal & 0 & 1 & 0 & 2 & $49 \%$ \\
\hline PFS & Base metal & 0 & 0 & 1 & 0 & $100 \%$ \\
\hline MRE & Porphyry & 1 & 4 & 1 & 0 & $5 \%$ \\
\hline PEA & Porphyry & 1 & 0 & 0 & 0 & $0 \%$ \\
\hline \multirow[t]{2}{*}{ MRE } & Rare metal & 0 & 4 & 0 & 0 & $24 \%$ \\
\hline & & 9 & 29 & 10 & 2 & $23 \%$ \\
\hline
\end{tabular}




\section{Density: Bulk in-situ or SG?}

used (Abzalov, 2013). The density of representative samples should be measured and recorded at appropriate intervals, using a method appropriate for the sample material. The determination used should recognize the type of material and mitigate the characteristics of the samples - core, drill chips, underground channel samples etc. Even a few per cent error in the bulk density determination could result in a significant change in the economic viability of the project or mine, particularly if it is a marginal project/mine. A fundamental understanding of what must be measured should be the basis for the method of measurement. The dry in-situ bulk density needs to be determined and reported as tons per cubic metre $\left(\mathrm{t} / \mathrm{m}^{3}\right)$.

\section{Methods of measurement}

Due to the economic limitations of acquiring data, sophisticated estimation and interpolation methods to estimate the characteristics such as in-situ bulk density of the material are used based on sample density data occurring at known data-points. Importantly, the data at the known points must be reliable and measure the required parameter. If the wrong density measurement is made, or the data from different points is measured incorrectly because of variations in the deposit, methods of measurements, or poor moisture corrections, the interpolation between these points will not be valid. An assessment of the likely bias in sample selection for more solid sticks of core and the possible contribution of voids in the bulk rock mass also need to be considered and discussed in any bulk density estimate and reporting.

The use of a prescriptive approach to the method of density determination is not advocated (Lipton, 2001). It is noted that a deposit is seldom going to have a homogenous density, and this will change with the rock type, rock thickness, weathering, and oxidation encountered. The choice of methods of density determination for a particular deposit or project will depend on the physical characteristics of the mineralization, the type of samples that are available or may reasonably be collected, the equipment that is available, and the stage of advancement of the project (Lipton, 2001). The guiding premise should be that determination of the bulk density of the deposit and adjoining non-mineralized material is as important a part of the evaluation programme as determination of the volume or the grade of mineralization. Suitable Quality Assurance/Quality Control (QA/ QC) procedures should be established to monitor and correct for anomalous readings and maintain a high-quality data-set. Lipton (2001) and Lipton and Horton (2014) present extensive guidance on sample collection and preparation, and measurement of sample density for use in bulk density estimates.

To accurately measure the sample density the volume and mass need to be accurately determined. As the samples being tested are generally small, the accuracy of measurement is very important. The most reliable material for the determination of sample density is core samples. However, the core may be inhomogeneous or more porous than expected, and this may lead to a bias in the selection of solid lengths of core or the incorrect application of a density measurement. Various methods could be used for density measurement, as described below.

\section{Calliper}

The volume of core is measured physically after dressing the core to represent a cylinder as closely as possible. The ends are cut square and the measurements made with precision devices such as simple outside callipers and Vernier callipers. The calliper method measures the dimensions of the core. This is potentially inaccurate as the core may not be regular in shape, with small variations is diameter as well as irregular ends. The method is very simple but depends on the ability to accurately dress the core to the shape of a cylinder. The mass is also relatively simple to determine, although care is required to ensure that the sample is dry before determining the dry bulk density.

\section{Pycnometer}

The advantage of this method is that the volume of an irregular sample can be determined directly. Gas pycnometers determine the volume by calculating the pressure change resulting from the displacement of gas by a solid object. Pycnometry is a very accurate method for the measurement of the density of a solid. As geological samples are pulverized before using a pycnometer the fabric of the rock is destroyed and any voids, pore spaces etc. are eliminated, making the pycnometer method generally unsuitable for the measurement of bulk density. Commonly, field geologists obtain details of laboratory procedures and select the density determination without consideration of the methodology used. This is on occasion a result of not having suitable equipment on site to accurately measure the bulk density and so relying on the laboratory to provide the necessary results.

\section{Water displacement}

Water displacement methods are very practical ways to determine bulk density as they overcome the most difficult requirement; that of determining the volume of an irregular shape, by measuring the volume of water displaced when the sample is immersed in water. There are a number of variations to the basic method depending on the physical characteristics of the sample, the porosity of the sample, the necessity to seal the sample, and the available equipment. Lipton (2001) presents six methods for the determination of sample density using water displacement. Commercially available equipment has made this method relatively simple to use. Generally, the core lengths are in the order of 10-20 cm, however larger equipment may allow longer sample lengths to be tested.

The method is based on the Archimedes Principle as the submerged sample experiences an upward force equal to the weight of fluid it displaces. In practice water is the best fluid to use. The volume is thus the difference of the weight of the sample as measured in water and as measured in air.

Practical aspects that should be considered are the nature of the sample, the water (composition and temperature), and air pressure. The accuracy of the measured density will depend on the ability of the water to infiltrate through any open pores/ fractures within the samples structure. Of most significance is the nature of the sample and specifically whether there are voids, or if the sample is porous and permeable. Some preparation may be required such as the application of a wax or a quick-drying spray to seal the sample. The sample is weighed and then dipped in molten wax, and once dried, weighed again. Wrapping with clingwrap has been shown to change the buoyancy of the sample, which would affect the density measurement (Lipton and Horton 2014). The effect of temperature on the density of water is very small (Capano, 2000). Changes in temperature of the sample may produce measurable changes in its density because of volume changes in the sample (Capano, 2000). The effect of changes in atmospheric pressure is negligible (Capano, 2000). The density 


\section{Density: Bulk in-situ or SG?}

of the water may be influenced by dissolved solids such as salt (seawater has a density of $1.02-1.05 \mathrm{t} / \mathrm{m}^{3}$ ). The use of pure water is therefore recommended. As for metalliferous deposits the dry bulk density is required, the contained moisture needs to be driven off prior to the density determination, or measured so that the dry density can be calculated.

\section{Pycnometer vs water displacement methods}

Jarman (2011) evaluated three different data-sets to demonstrate that there is a significant difference between the pycnometer and water displacement methods of sample density determination (Figure 2). The measurements are for the most part above the line that would indicate that the Archimedes and pycnometer values are the same, i.e. the pycnometer determination is higher than the real value. The differences showed that the pycnometer determined a bulk density higher by $5.28 \%, 5.55 \%$, and $4.92 \%$. This is in line with other determinations such as $7 \%$ for Eland Palatium Mine (Lomberg et al., 2004) and 2\% for Union mine (de Vries, 2013).

\section{Density of tailings storage facilities}

As tailings storage facilities (TSFs) and waste dumps are frequently re-mined, the determination of the density is important when considering the feasibility of the operation. Tailings densities are notoriously difficult to determine as the material has been dumped and, depending on the size distribution, includes voids. Tailings dumps are effectively dams filled with fine-grained material. The surface may be dry but immediately below the surface the material will be wet. The density determination poses many issues as the material can seldom be recovered without the drill-hole or excavation caving in or collapsing. The density is also expected to change with depth and position on the TSF, with the centre being finer graded than the perimeter. These aspects must be considered when selecting the method of bulk density determination.

It is generally best to determine the density on site by excavating a hole and measuring the volume directly. The weight can be determined by appropriate means, including a scale or weighbridge, depending on the size of the sample. The density will need to be corrected for moisture content.

A small hole $(30 \times 30 \times 30 \mathrm{~cm})$ on the surface with defined dimensions may be excavated and the material weighed on site with the moisture content, or alternatively the sample may be sealed, and the weight determined prior to drying of the material to determine the moisture content and thus allow the calculation of the dry bulk density. The hole should not be too big or else weighing the material is a potential problem. The hole dimensions can be determined by measurement, or the volume determined directly by lining with plastic/latex and filling with water.

\section{Reliable dry bulk density database}

The Competent Persons responsible for Mineral Resource estimation must ensure that the bulk density is reliable and robust. They must ensure that the sampling methodology is sound and appropriate for the deposit, that the process is overseen, and that various $\mathrm{QA} / \mathrm{QC}$ procedures are implemented, and provide a discussion on the estimation of the bulk densities from the sample density results. If the determination of the dry sample density is included in the assay request form without any consideration to the method used and its implication, the final results may be compromised. It is suggested that a moisture determination is also made to assess the degree of drying, given that the dry bulk density is expected to be on the same basis as the dry assay grades.

It is expected that there will be some variability of bulk density within the volume that is being estimated. The variability is deposit-specific and may be complicated by the delineation of estimation domains, rock types, alteration, structural features, and degrees of weathering. Weathering or alteration, for instance, are likely to decrease the rock bulk density and increase the porosity. This may result in high variability in the host rock bulk density that will require the appropriate method of data collection, sample preparation, and proper attention when estimating the bulk density.

Typical hard rock bulk density values for in-situ deposits range from $1.8 \mathrm{t} / \mathrm{m}^{3}$ to $5 \mathrm{t} / \mathrm{m}^{3}$. An assessment of the database to ensure that there are no outliers is important. Outliers may be the result of transcription errors or faulty equipment. If the deposit being assessed is a TSF or dump, the range will be considerably different.

In some instances, such as iron ore deposits, it is necessary to determine the relationship between the haematite/magnetite and the bulk density as the iron content is the major component of the rock $(>50 \%)$. A regression curve may be used to determine the relationship (Figure 3). A similar approach is frequently applied between ash content and density for coal deposits.

\section{Conclusions}

Bulk density is an essential and critical component of a Mineral Resource estimation as it affects the determination of asset value through the calculation of tonnage and metal content. The sample-related data used for the dry bulk density determination and the methods used to measure and model the variably of the dry bulk density are seldom presented at the same level of detail or confidence as grade data, as the databases are frequently very different. It is stressed that density must be seen as a variable with the same status as a grade, given its use in estimating tonnage and contained metal.

The use of a prescriptive approach to the method of density determination is not advocated for deposits which have been drilled out with core drill-holes, provided an appropriate method is applied with referenced results. It is advocated that the choice of method(s) for determining the bulk density of a particular deposit is the responsibility of the Competent Person and will depend on the physical characteristics of the mineralization, rock types/characteristics, and the available sampling equipment.

\section{References}

ABZALov, M.Z. 2013. Measuring and modelling of dry bulk rock density for mineral resource estimation. Transactions of the Institutions of Mining and Metallurgy: Section B. Applied Earth Science, vol. 122, no. 1. pp. 16-29.

ArseneAu, G.J. 2013. Estimation of bulk density for mineral resource reporting. Internal SRK Report

AusIMM. 2001. Mineral Resource and Ore Reserve estimation - The AusIMM guide to good practice. Edwards, A.C. (ed.). Monograph 23. Australasian Institute of Mining and Metallurgy: Melbourne.

CIM. 2018. Mineral Exploration Best Practice Guidelines. Prepared by the Canadian Institute of Mining, Metallurgy and Petroleum (CIM) Mineral Resource and Mineral Reserve Committee. Adopted by CIM Council November 23, 2018. Montreal.

Dominy, S.C., Noppe, M.A., and Annels, A.E. 2002. Errors and uncertainty in mineral resource and ore reserve estimation: The importance of getting it right. Exploration and Mining Geology, vol. 11, no. 1-4. pp. 77-98. 
Density: Bulk in-situ or SG?
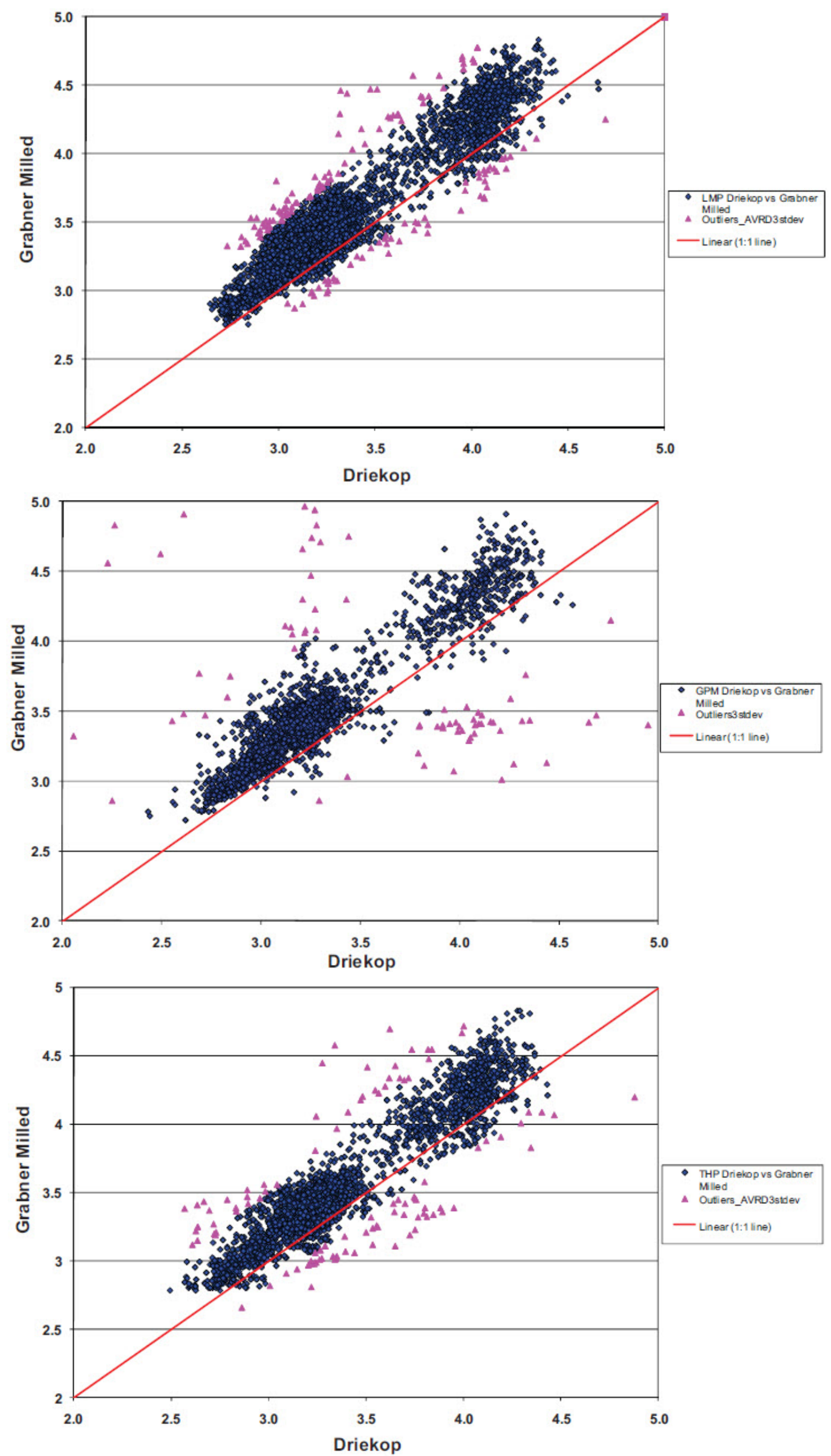

Figure 2-Graphical representation of the difference between pycnometer ( $y$-axis $\left.-t / m^{3}\right)$ and water displacement methods $\left(x-a x i s-t / m^{3}\right)(J a r m a n, 2011)$ 


\section{Density: Bulk in-situ or SG?}

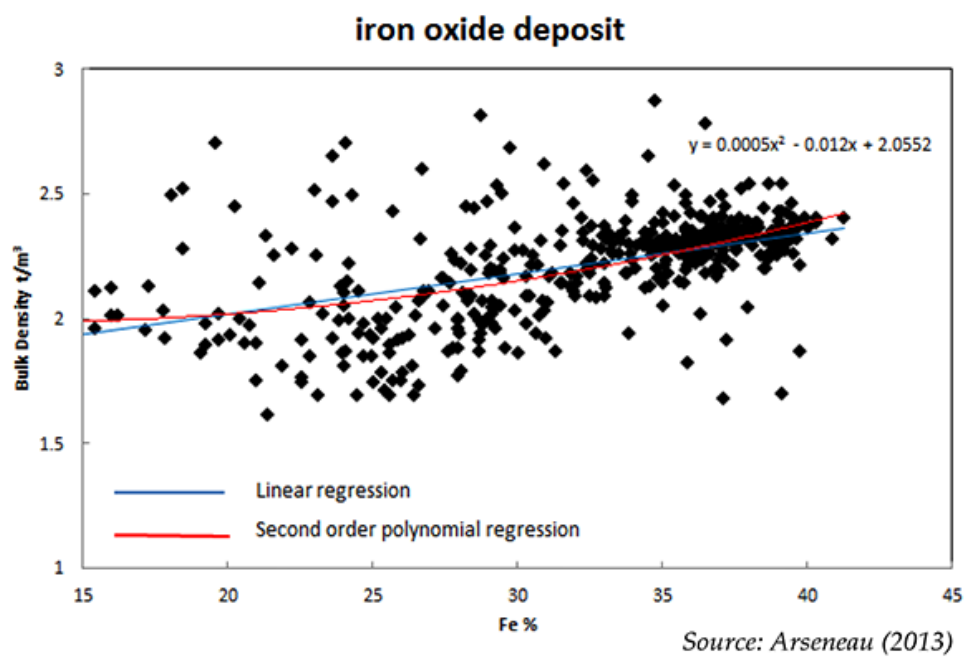

Figure 3-A typical regression curve for an iron ore deposit (Arseneau, 2013)

JARMAN, D.J. 2011. Comparison of rock density determination methods used in South African platinum mines for resource planning purposes. MSc thesis, University of Pretoria.

LiPTON, I.T. 2001. Measurement of bulk density for Resource Estimation. Mineral Resource and Ore Reserve estimation - The AusIMM guide to good practice. Edwards, A.C. (ed.). Monograph 23. Australasian Institute of Mining and Metallurgy, Melbourne. pp. 57-66
LiPTon, I.T. and Horton, J.A. 2014. Measurement of bulk density for resource estimation - methods, guidelines and quality control. Mineral Resource and Ore Reserve Estimation - The AusIMM Guide to Good Practice. 2nd edn. Monograph 30. Australasian Institute of Mining and Metallurgy: Melbourne.

Preston, K.B. and SAnders, R.H. 1993. Estimating the in situ relative density of coal. Australian Coal Geology, vol 9. pp. 22-26.

\section{A long distance relationship that works.
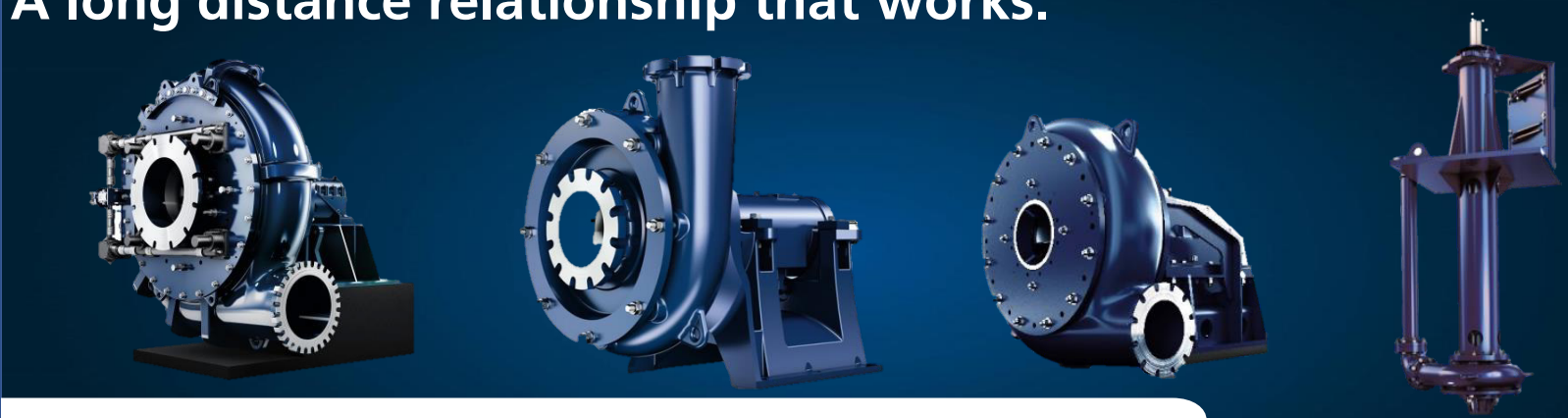 \\ Wear Resistant, High Performance - Global Quality Mining Pumps.}

KSB South Africa is based in Johannesburg with modern manufacturing and sales facilities. With nine additional sale branches in South Africa, four branches in Sub Saharan Africa (West, Central and East Africa).

$\mathrm{KSB}$ is represented throughout the whole country.

KSB South Africa, manufactures our globally recognised pump solutions locally to the most stringent international and local quality standards. Our innovative solutions provide for the most demanding and corrosive slurry applications with superior abrasion resistance.

At KSB South Africa, we manufacture and service your slurry systems. We work with you one on one to find the best solution for your slurry and process pumping applications. Let us be your partner and work with you to help you meet your production goals. One team with one goal.

KSB Pumps and Valves (Pty) Ltd www.ksb.com/ksb-za 